\title{
Current Trends of Engineered Nanoparticles (ENPs) in Sustainable Agriculture: An Overview
}

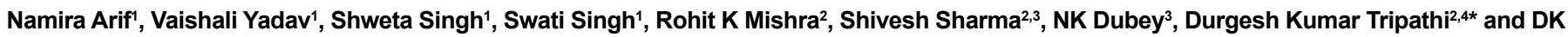 \\ Chauhan $^{1 *}$
}

${ }^{1} D D$ Pant Interdisciplinary Research Laboratory, Department of Botany, University of Allahabad, Allahabad, Uttar Pradesh, India

${ }^{2}$ Centre for Medical Diagnostic and Research, Motilal Nehru National Institute of Technology Allahabad, Allahabad, Uttar Pradesh, India

${ }^{3}$ Department of Biotechnology, Motilal Nehru National Institute of Technology Allahabad, Allahabad, Uttar Pradesh, India

${ }^{4}$ Centre of Advanced Study in Botany, Banaras Hindu University, Varanasi, Uttar Pradesh, India

\begin{abstract}
Nanotechnology is an interesting area of multifaceted research in agricultural perspective. This technology incorporates the manufacturing of material at nano level. Nanoparticles (NPs) have now become an integral part of research because of their unique features like their size, shape and surface reactivity. In agriculture sector engineered nanoparticles (ENPs) i.e., metal NPs, metal oxide NPs and Carbon Nano Tubes (CNTs) etc has been used in the form of nanofertilizers and nanopesticide/ herbicides. Therefore, the appropriate use of nanoparticles could provide a proficient sustainable platform to achieve the food requirement of global massive population. As of the application of nanotechnology to agriculture and food industry is outturn in enhanced crop yield with better food quality as well as safety. Inspite of the significances of nano-material, negative outcomes should also be taken in consideration before applying it on a large scale.
\end{abstract}

Keywords: Sustainable agricultural; Engineered nanoparticles (ENPs); Crop yield; Food quality; Safety

\section{Introduction}

Nanotechnology is an enthralling scientific field, which offers multidirectional research in the area of agriculture as well as biotechnology, now its time to unraveling the novel applications with their mode of action [1]. Now, current agricultural sector demands a continuous innovative research to meet out the food requirement of enormously increasing population, therefore nanotechnology plays a promising role by influencing crop production in this modern technical era [2]. Agriculture is the backbone of the majority of developing countries; approximately $60 \%$ of population depends on agriculture for their livelihood [3]. Nanotechnology influences the agriculture productivity with the relevance of Nanofertilizer, nanopesticides or nanoherbicides and nanocoating, these are smart delivery system to plants, also the various industries creating formulations with nanoparticles $(100-250 \mathrm{~nm})$ to enhance their actions by increasing nanoparticles solubility in water [3,4] (Figure 1). The synthesis of engineered nanoparticles (ENPs), processing of nanomaterials, and their applications comes under the area of nanotechnology and therefore excellent efforts have been made to synthesize biogenic engineered nanoparticle (ENPs) [5,6] with a unique blend of antibacterial and photocatalytic properties for critical applications [6]. Nanomaterials properties vary from the bulk materials of same composition. The synthesized nanoparticles provide large specific surface area and also bears huge amount of atom for chemical reactions [7]. Engineered nanoparticles have distinctive physicochemical properties rather than other particle that exist in nature $[1,8]$. These are the two dimensional particles that generally formed between 1-100 nm range $[9,10]$. Effectiveness of ENPs on different plants are determined using different parameters such as chemical composition, specific size, surface covering, reactivity, and their effective dose regarding plants [11]. The plenty of scientific studies, reported that the synthesized nanoparticles have positive and negative consequences on the plant growth that depends on the different size and other parameters of engineered nanoparticles $[1,12]$. Much progress has already been accomplished in this area over the past decades however, proficient compilation in the form of grave review on various aspects of this topic has not been explored properly. This review therefore, attempts to provide the plenty of information based on several studies together at one place.

\section{Applications of Nanoparticles on Agriculture}

Nanotechnology cannot be confused as the one technology but it is a group of miscellaneous technologies working at the nano level [13]. Alone in the agriculture prospects there are extensive potential applications of nanotechnology, for instance; nanotechnology facilitates release of chemicals to modern agricultural system (Figure 1) and also aid nano-sensors for the observation of environmental stress [14], use in maintaining crop setting, and combating against the environmental stresses including diseases via enhancing plant qualities $[13,15]$. According to Parisi et al. [16] european commission appraised that in developed countries, pesticide formulations and nanosensors are the main applications of nanotechnology which are very useful in applied and sustainable agricultural practices. As the nanotechnology facilitated applications are promising to the sustainable crop production, it also delivers multiple stresses in the way of plant growth and development. Numerous positive and negative impacts of nanoparticles were studied by several workers in the area of agricultural sector, Fraceto et al. [17] reported about some recent studies that focuses on the positive

${ }^{*}$ Corresponding authors: Durgesh Kumar Tripathi, Centre for Medical Diagnostic and Research, Motilal Nehru National Institute of Technology Allahabad, Allahabad-211 004, Uttar Pradesh, India, Tel: +8081022287; E-mail: dktripathiau@gmail.com

DK Chauhan, DD Pant Interdisciplinary Research Laboratory, Department of Botany, University of Allahabad, Allahabad-211 002, Uttar Pradesh, India, Tel: +8081022287; E-mail: dkchauhanau@yahoo.com

Received August 02, 2016; Accepted August 22, 2016; Published August 26 , 2016

Citation: Arif N, Yadav V, Singh S, Singh S, Mishra RK, et al. (2016) Current Trends of Engineered Nanoparticles (ENPs) in Sustainable Agriculture: An Overview. J Environ Anal Toxicol 6: 397. doi: 10.4172/2161-0525.1000397

Copyright: ( 2016 Arif $\mathrm{N}$, et al. This is an open-access article distributed under the terms of the Creative Commons Attribution License, which permits unrestricted use, distribution, and reproduction in any medium, provided the original author and source are credited. 
Citation: Arif N, Yadav V, Singh S, Singh S, Mishra RK, et al. (2016) Current Trends of Engineered Nanoparticles (ENPs) in Sustainable Agriculture: An Overview. J Environ Anal Toxicol 6: 397. doi: 10.4172/2161-0525.1000397
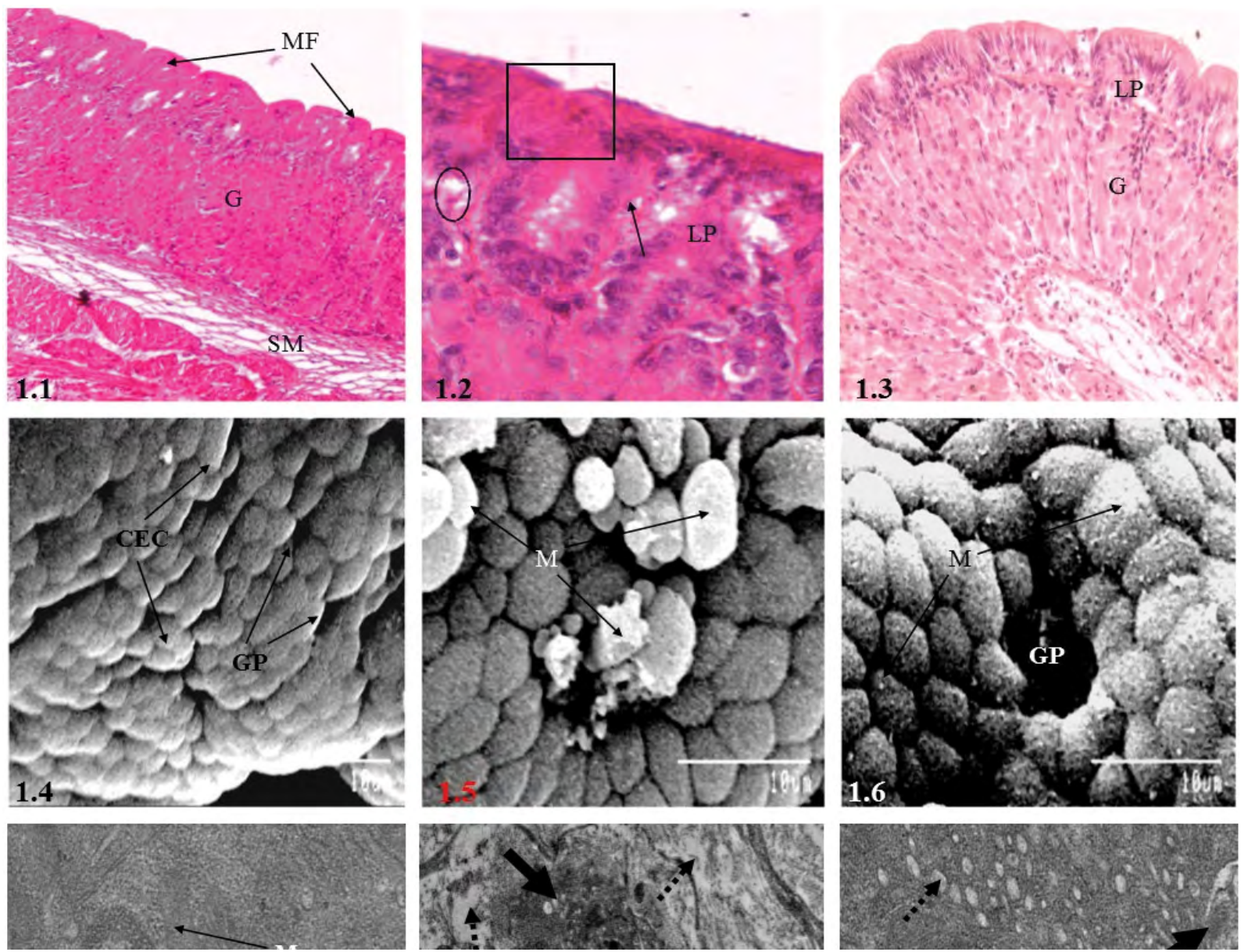

Figure 1: Nanoparticles (NPs) (metal NPs, Metal oxide NPs and carbon nanotubes) at optimum dose increases chlorophyll content, release of required chemicals, nutrient uptake, NPs solubility, cell elongation, germination rate, growth parameters, microbial activities and crop productivity [3,4,12,15-17,20-41], while at high dose cause phytotoxicity by reducing crop yield and productivity $[26-33,38]$.

potential side of nanoparticles on agricultural area. Carbon nanotubes and nanoparticles of $\mathrm{Au}$ (gold), $\mathrm{SiO}_{2}$ (silicon oxide), $\mathrm{ZnO}$ (zinc oxide), and $\mathrm{TiO}_{2}$ (titanium oxide) nanoparticles by increasing essential metalnutrient uptake reported to enhances the plant development $[17,18]$. In the support of above statement, Morteza et al. [19] suggested that $\mathrm{TiO}_{2} \mathrm{NPs}$ enhanced crop yield of corn (Zea mays L.) by improving the chlorophyll ( $\mathrm{a}$ and $\mathrm{b}$ ), carotenoids and anthocyanins contents with their concentration of $0.01 \%$ and $0.03 \%$ respectively. Similar studies were elaborated with positive effects of $\mathrm{TiO}_{2} \mathrm{NPs}$ in canola (Brassica napus) [20], Solanum lycopersicum (L.) and Vigna radiata (L.) [21]. While study by Da Costa and Sharma [22] found phytotoxicity of $\mathrm{TiO}_{2} \mathrm{NPs}_{\mathrm{N}}$ Oryza sativa which was observed through decrease in seedling growth, photosynthetic activity and biochemical processes at their elevated concentration (1000 ppm). Tripathi et al. [23] eraborately reviewed about the number of phytotoxicity created by manufactured nanoparticles in different plants on the ground of physiological, biochemical, genetic and molecular. Different negative effects were also reported by Song et al. [24] on Seeds of Brassica napus, Lactuca sativa and Phaseolus vulgaris. Study on maize seed germination with $\mathrm{ZrO}_{2}$ (zirconia), $\mathrm{SiO}_{2}$ (silica), $\mathrm{Al}_{2} \mathrm{O}_{3}$ (Alumina) and $\mathrm{TiO}_{2}$ (titania) nanoparticles resulted in exhibition of reduced seed germination at the same time $\mathrm{SiO}_{2} \mathrm{NPs}$ and zirconia $\left(\mathrm{ZrO}_{2}\right)$ increased seed germination and root elongation, whereas root inhibited by the application of $\mathrm{Al}_{2} \mathrm{O}_{3}$ and $\mathrm{TiO}_{2}$ [25]. In the case of $\mathrm{ZnO}$ NPs, it has significantly influences the growth, yield, and zinc content of maize grains [26]. Analogous results were obtained by Adhikari et al. [27] on maize plant. On the contrary, ZnO NPs have reported to exhibit phytotoxicity in corn (Zea mays L.) and cucumber (Cucumis sativus L.) [28]. Most of the silver nanoparticles (AgNPs), based studies showed the negative implications on growth and development of agricultural crop [29] including the modification at molecular level in different plant species such as Mung bean (Vigna radiata L.) [30], Arabidopsis thaliana [31,32], and Oryza sativa [33,34]. Similarly, Da Costa and Sharma [35] propounded exogenous application of CuO NPs (copper oxide) in rice (Oryza sativa, var. Jyoti) that resulted in decrease in germination rate, growth parameters and biomass. Simultaneously, Liu et al. [36] documented that $\mathrm{CuO}$ NPs and $\mathrm{ZnO}$ NPs display toxicity on the germination of lettuce (Lactuca sativa) seeds. On the other side $\mathrm{Cu}$ being an essential micronutrient, $\mathrm{Cu}$ NPs positively influence growth of maize (Zea mays L.) plant by assimilating into the routes of plant and regulating the enzymatic activies [37]. Mn and FeNPs delivery reported to display positive impacts on the seed germination and were also enhanced agronomic productivity. In accordance with most of the experimental report metal nanoparticles and their oxides AgNPs (Hordeum vulgare L.) [38], AuNPs (Brassica juncea) [39], TiNPs (wheat) [40], $\mathrm{Fe}_{3} \mathrm{O}_{4} \mathrm{NPs}$ (iron oxide) (wheat) [41] positively responds to the crop productivity. In case of carbon based nanomaterials Carbon Quantum Dots (CQDs), Graphene Quantum Dots (GQDs), Graphene Oxide (GO), and Single-Walled Carbon Nanotubes (SWCNTs) an 
Citation: Arif N, Yadav V, Singh S, Singh S, Mishra RK, et al. (2016) Current Trends of Engineered Nanoparticles (ENPs) in Sustainable Agriculture: An Overview. J Environ Anal Toxicol 6: 397. doi: 10.4172/2161-0525.1000397

Page 3 of 5

experimental study on bean sprout revealed phytotoxicity in a dose dependent manner [42]. Whereas, a plenty of studies on carbon nanoparticles or carbon nanotubes on different plants species such as, tomato (Lycopersicon esculentum M.) [43], mustard (Brassica juncea) [44] and rice (Oryza sativa L.) [45] manifested enhance germination rate, increase in growth parameters resulted to improve crop production. Furthermore, multi-walled nanotubes (o-MWCNTs) were found effective in increase of root cell elongation in wheat plant and also played an important role to step up dehydrogenase activity thus increase in growth and biomass production [46]. Nanoparticles can also be incorporated into the preparation of pesticides, insecticides and insect repellants for securing the crop against insect and pest [4749]. Relevant to the above statement, study reveals the nature of nonfunctionalized and amino-functionalized multiwall Carbon Nanotubes (CNT) in controlling the pesticide availability to lettuce (Lactuca sativa L.) seedlings. According to which Non-functionalized CNT $(88 \%$ and $78 \%$ ) and amino-functionalized CNT (57\% and 23\%) was found to reduce the root-shoot pesticide content respectively. Therefore, in respect to agricultural field it suggests an imperative application of engineered nanomaterials for leafy vegetables [50]. Nanoparticles not only helps in improving crop yield by increasing mineral availability (Maize) [51], but also improve the crop yield by alleviating the heavy metal toxicity, UV-B induced stress and other abiotic stresses. As documented by Tripathi et al. [52] SiNps (silicon) effectively reduce UV-B induced stress in wheat seedling by the enhanced antioxidant mechanism. Si NPs has been reported to potentially remove chromium [Cr(VI)] mediated toxicity in Pisum sativum (L.) seedlings by suppressing the $\mathrm{Cr}$ accumulation and increasing nutrient availability to the plant [53]. Si NPs is also found to be more efficient than $\mathrm{Si}$ in removing different level of arsenate $(25$ and $50 \mu \mathrm{M})$ mediated toxicity in maize cultivar and hybrid by increasing ascorbate-glutathionecycle (AsA-GSHcycle) components and reducing oxidative stress and arsenate accumulation [54]. According to Siddiqui and Al-Wahaibi, [55] Nano-silicon dioxide ( $\left.\mathrm{nSiO}_{2}\right)$ significantly effects seed germination of tomato (Lycopersicum esculentum Mill.). In addition to metal and metal oxide nanoparticles, fungal cell wall polymer (chitosan) based nanoparticles (CWP-NP) has been proved to enhanced yield of tomato by protecting the plant against Fusarium oxysporum f. sp. lycopersici infected wilt disease [56]. Multi-walled carbon nanotubes exposed to broccoli under salinity stress reported to induce water uptake and transportation by increasing the net assimilation of $\mathrm{CO}_{2}$ and aquaporin transduction, also slightly changes the properties of salt stressed root plasma membrane to alleviate the stress and increasing growth [57]. Nanomaterials have the potential to respond with soil biota. $\mathrm{TiO}_{2} \mathrm{NPs}$,

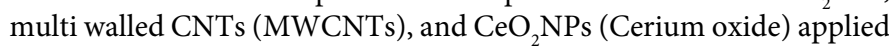
in agricultural soil divulges to fix the biological nitrogen by rhizobia and arbuscular mycorrhizal (AMV) fungi on red clover [58].

Nowadays, nanofertilizers have become immensely interesting area of study for the researchers for sustainable agriculture crop production. Abdel-Aziz et al. [59] gave the exogenous foliar application of chitosan NPs laden with NPK (nitrogen, phosphorus and potassium) fertilizers to the wheat plant grown in sandy soil resulted in elevation in yield index variables (harvest index, crop index and mobilization index). Ajirloo et al. [60] reviled the potential role of nanofertilizers for instance, K NanoFertilizer and N Bio-Fertilizer in improving the yield components of tomato. Analogous study was also reported in red bean (Phaseolus vulgaris L.) [61]. Davarpanah et al. [62] demonstrated his findings by giving the exogenous foliar application of zinc and boron nanofertilizers to the pomegranate (Punica granatum cv. Ardestani), their application increased the yield and quality of pomegranate fruit and also improved the tree nutrient availability. Recent study advocated that apatite NPs could be used as a phosphorus $(\mathrm{P})$ fertilizer that sustained $\mathrm{P}$ availability as required by the plant $[63,64]$. Nanotechnology now replacing the traditional food in agri-food industry by launcing nanomanufactured products, for instance, Canola Active Oil, a cooking oil enclosing designed "nanodrops") (Shemen Industries, Tel Aviv, Israel) [65], Nanotea (Tea) (Qinhuangdao Taiji Ring Nano-Products Co., Ltd., Hebei, People's Republic of China), Nanoceuticals Slim Shake Chocolate that contains cocoa-infused "Nano Clusters" which does not requires extra sugar [2].

\section{Conclusion}

In the present era, world's 7 billion populations [66] have undergone to face the tremendous challenges in multiple platforms, especially in the field related to food and agriculture. Food is the primary requirement for the survival of population. Therefore, food requirement entails a huge pressure on the agricultural sectors for their demand [67]. However, there is a dire need to evolve and incorporate such technique that could maintain sustainable agricultural crop production. Thus, nanotechnology has become an efficient field for research in agricultural production [2]. Nations Millennium Development Goals (MDG's) have set goals for meeting the needs of millions of people who are facing lack of access basic human needs such as, safe drinking water, energy source, health and education. Therefore, nanotechnology could become boon for the welfare of mankind by achieving the MDG's, but with a watchfulness over the possible risks of nanotechnology for developing countries [68-70]. In case of nanotechnology the arrival of manufactured nanomaterials fetches multiple threats related to agri-food industry. But it does not means that the use of ENPs could only bring risk, therefore there is a plenty of scientific studies are reported in support of the novel application of nanoparticles in the field of agriculture productivity. Because of their unique feature like size, shape, density, surface reactivity and their targeting potential researchers are using nanomaterials of different ranges through various applications, with the rise of research on using nanoscale materials (carbon NPs, metal NPs, metal oxide NPs) they become helpful for the crop management, for attaining the nutrient requirement, enhancing microbial activities, suppressing the disease availability, increasing nutrient availability to the plant and also elevating the crop yield and productivity [71]. Nowadays nanoparticles like metal and metal oxide nanoparticles, carbon based nanotubes such as carbon quantum dots, graphene quantum dots, graphene oxide, and single and multi-walled carbon nanotubes are manipulated in such a way as it can be used to improve crop yield and also alleviating toxicity in the form of nanofertilizers, nanopesticides, nanoherbicides, incenticides and food additives and food manufacturing. Therefore, nanotechnology has remarkable potential and application for bringing sustainable agriculture.

\section{Future Prospects}

Several studies on nanoparticles-plant interaction have already been made. However, a large number of studies are still required to enhance the plant growth with least adverse outcome. In spite of nano incorporated positive implications on agriculture, risk assessment should also be taken into consideration to maintain long term agricultural sustainability. Therefore, the focus should made on the diverse application of nanoparticles in area related to agriculture, such as plant growth and development including availability of soil microorganism, macro and micro- nutrient availability, mitigation of different abiotic stress and the possibilities of using nanomaterials for 
Citation: Arif N, Yadav V, Singh S, Singh S, Mishra RK, et al. (2016) Current Trends of Engineered Nanoparticles (ENPs) in Sustainable Agriculture: An Overview. J Environ Anal Toxicol 6: 397. doi: 10.4172/2161-0525.1000397

Page 4 of 5

sustaining the agriculture production that allows risk free environment in the near future. Thus, the current trends of Engineered Nanoparticles (ENPs) research demonstrated the potential landmark in sustainable agricultural through the improvement of quality food production with minimizing its adverse impact on human health as well as environment. On the other hand its concentration dependent behavior with living system is a major threat that must be analyze before its wide application to avoid its harmful impact.

\section{Conflict of Interest}

Authors declare that they have no conflict of interest.

\section{Acknowledgments}

Dr. Dugesh Kumar Tripathi is thankful to University Grants Commission, New Delhi for providing Dr. D. S. Kothari Post Doctoral Fellowship (DSKPDF) and Dr. Rohit K. Mishra is thankful to Science and Engineering Research Board (SERB), Department of Science and Technology, New Delhi for providing Fast Track Young Scientist.

\section{References}

1. Siddiqui MH, Al-Whaibi MH, Firoz M, Al-Khaishany MY (2015) Role of nanoparticles in plants. In: Nanotechnology and Plant Sciences. Springer International Publishing, pp: 19-35.

2. Sekhon BS (2014) Nanotechnology in agri-food production: an overview. Nanotechnology, science and applications 7: 31.

3. Prasad R (2014) Synthesis of silver nanoparticles in photosynthetic plants. Journal of Nanoparticles Article ID 963961, pp: 1-8.

4. Marchiol L (2012) Synthesis of metal nanoparticles in living plants. Italian $J$ Agro 7: 37

5. Prasad R, Pandey R, Barman I (2016) Engineering tailored nanoparticles with microbes: quo vadis? Wiley Interdiscip Rev Nanomed Nanobiotechnol 8: 316-330.

6. Aziz N, Faraz M, Pandey R, Shakir M, Fatma T, et al. (2015) Facile algaederived route to biogenic silver nanoparticles: synthesis, antibacterial, and photocatalytic properties. Langmuir 31: 11605-11612.

7. Alidoust D, Isoda A (2013) Effect of $\mathrm{yFe}_{2} \mathrm{O}_{3}$ nanoparticles on photosynthetic characteristic of soybean (Glycine max (L.) Merr.): foliar spray versus soil amendment. Acta Physiol Plant 35: 3365-3375.

8. Giraldo JP, Landry MP, Faltermeier SM, McNicholas TP, Iverson NM, et al. (2014) Plant nanobionics approach to augment photosynthesis and biochemical sensing. Nature Materials 13: 400-408.

9. Klaine SJ, Alvarez PJ, Batley GE, Fernandes TF, Handy RD, et al. (2008) Nanomaterials in the environment: behavior, fate, bioavailability, and effects. Environ Toxicol Chem 27: 1825-1851.

10. Peralta-Videa JR, Zhao L, Lopez-Moreno ML, de la Rosa G, Hong J, et al. (2011) Nanomaterials and the environment: a review for the biennium 20082010. J Hazard Mater 186: 1-15.

11. Khodakovskaya MV, de Silva K, Biris AS, Dervishi E, Villagarcia H (2012) Carbon nanotubes induce growth enhancement of tobacco cells. ACS Nano 6: 2128-2135.

12. Ma X, Geiser-Lee J, Deng Y, Kolmakov A (2010) Interactions between engineered nanoparticles (ENPs) and plants: phytotoxicity, uptake and accumulation. Sci Total Environ 408: 3053-3061.

13. Forsberg EM, de Lauwere C (2013) Integration needs in assessments of nanotechnology in food and agriculture. Etikk i praksis-Nordic J Appl Ethics 7: 38-54.

14. Ditta A, Arshad M, Ibrahim M (2015) Nanoparticles in sustainable agricultura crop production: Applications and perspectives. In: Nanotechnology and Plant Sciences. Springer International Publishing, Pp: 55-75.

15. Chen H, Yada R (2011) Nanotechnologies in agriculture: New tools for sustainable development. Trends Food Sci Tech 22: 585-594.

16. Parisi C, Vigani M, Cerezo ER (2014) Proceedings of a Workshop on " Nanotechnology for the agricultural sector: from research to the field". Institute for Prospective and Technological Studies, Joint Research Centre, (No. JRC89736).
17. Fraceto LF, Grillo R, de Medeiros GA, Scognamiglio V, Rea G, et al. (2016) Nanotechnology in Agriculture: which innovation potential does it have? Front Environ Sci 4: 20.

18. Khot LR, Sankaran S, Maja JM, Ehsani R, Schuster EW (2012) Applications of nanomaterials in agricultural production and crop protection: a review. Crop Prot 35: 64-70.

19. Morteza E, Moaveni P, Farahani HA, Kiyani M (2013) Study of photosynthetic pigments changes of maize (Zea mays $\mathrm{L}$.) under nano $\mathrm{TiO}_{2}$ spraying at various growth stages. Springer Plus 2: 247.

20. Mahmoodzadeh H, Nabavi M, Kashefi H (2013) Effect of nanoscale titanium dioxide particles on the germination and growth of canola (Brassica napus). Journal of Ornamental and Horticultural Plants 3: 25-32.

21. Singh P, Singh R, Borthakur A, Srivastava P, Srivastava N, et al. (2016) Effect of nanoscale TiO2-activated carbon composite on Solanum lycopersicum (L.) and Vigna radiata (L.) seeds germination. Energy Ecol Environ 1: 131-140.

22. Da Costa MVJ, Sharma PK (2014) Influence of Titanium Dioxide Nanoparticles on the Photosynthetic and Biochemical Processes in Oryza sativa. Int J Rec Scient Res 6: 2445-2451.

23. Tripathi DK, Gaur S, Singh S, Singh S, Pandey R, et al. (2016) An overview on manufactured nanoparticles in plants: Uptake, translocation, accumulation and phytotoxicity. Plant Physiol Biochem.

24. Song U, Shin M, Lee G, Roh J, Kim Y, et al. (2013) Functional analysis of TiO nanoparticle toxicity in three plant species. Biol Trace Elem Res 155: 93-103.

25. Karunakaran G, Suriyaprabha R, Rajendran V, Kannan N (2016) Influence of $\mathrm{ZrO}_{2}, \mathrm{SiO}_{2}, \mathrm{Al}_{2} \mathrm{O}_{3}$ and $\mathrm{TiO}_{2}$ nanoparticles on maize seed germination under different growth conditions. let Nanobiotechnol 10: 1717-177.

26. Subbaiah LV, Prasad TNVKV, Krishna TG, Sudhakar P, Reddy BR, et al. (2016) Novel Effects of Nanoparticulate Delivery of Zinc on Growth, Productivity, and Zinc Biofortification in Maize (Zea mays L.). J Agric Food Chem 64: 3778-3788.

27. Adhikari T, Kundu S, Biswas AK, Tarafdar JC, Subba Rao A (2015) Characterization of Zinc Oxide Nano Particles and Their Effect on Growth of Maize (Zea mays L.) Plant. J Plant Nutr. 38: 1505-1515.

28. Zhang R, Zhang H, Tu C, Hu X, Li L, et al. (2015) Phytotoxicity of ZnO nanoparticles and the released $\mathrm{Zn}$ (II) ion to corn (Zea mays L.) and cucumber (Cucumis sativus L.) during germination. Environ Sci Pollut Res 22: 1110911117.

29. Tripathi DK, Singh S, Singh S, Srivastava PK, Singh VP, et al. (2016) Nitric oxide alleviates silver nanoparticles (AgNps)-induced phytotoxicity in Pisum sativum seedlings. Plant Physiol Biochem.

30. Nair PMG, Chung IM (2015) Physiological and molecular level studies on the toxicity of silver nanoparticles in germinating seedlings of mung bean (Vigna radiata L.). Acta Physiol Plant 37: 1-11.

31. Kaveh R, Li YS, Ranjbar S, Tehrani R, Brueck CL, et al. (2013) Changes in Arabidopsis thaliana gene expression in response to silver nanoparticles and silver ions. Environ Sci Technol 47: 10637-10644.

32. Nair PMG, Chung IM (2014) Assessment of silver nanoparticle-induced physiological and molecular changes in Arabidopsis thaliana. Environ Sci Pollut Res 21: 8858-8869.

33. Mirzajani F, Askari H, Hamzelou S, Schober Y, Römpp A, et al. (2014) Proteomics study of silver nanoparticles toxicity on Oryza sativa L. Ecotoxicol Environ Saf 108: 335-339.

34. Thuesombat P, Hannongbua S, Akasit S, Chadchawan S (2014) Effect of silver nanoparticles on rice (Oryza sativa L. cv. KDML 105) seed germination and seedling growth. Ecotoxicol Environ Saf 104: 302-309.

35. Da Costa MVJ, Sharma PK (2016) Effect of copper oxide nanoparticles on growth, morphology, photosynthesis, and antioxidant response in Oryza sativa. Photosynthetica 54: 110-119.

36. Liu R, Zhang H, Lal R (2016) Effects of Stabilized Nanoparticles of Copper Zinc, Manganese, and Iron Oxides in Low Concentrations on Lettuce (Lactuca sativa) Seed Germination: Nanotoxicants or Nanonutrients? Water Air Soil Pollut 227: 1-14

37. Adhikari T, Sarkar D, Mashayekhi H, Xing B (2016) Growth and enzymatic activity of maize (Zea mays L.) plant: Solution culture test for copper dioxide nano particles. J. Plant Nutr 39: 99-115. 
Citation: Arif N, Yadav V, Singh S, Singh S, Mishra RK, et al. (2016) Current Trends of Engineered Nanoparticles (ENPs) in Sustainable Agriculture: An Overview. J Environ Anal Toxicol 6: 397. doi: 10.4172/2161-0525.1000397

Page 5 of 5

38. Gruyer N, Dorais M, Bastien C, Dassylva N, Triffault-Bouchet G (2013) Interaction between silver nanoparticles and plant growth. In: International Symposium on New Technologies for Environment Control. Energy-Saving and Crop Production in Greenhouse and Plant Factory 1037: 795-800.

39. Arora S, Sharma P, Kumar S, Nayan R, Khanna PK, et al. (2012) Goldnanoparticle induced enhancement in growth and seed yield of Brassica juncea. Plant Growth Regul 66: 303-310.

40. Jaberzadeh A, Moaveni P, Moghadam HRT, Zahedi H (2013) Influence of bulk and nanoparticles titanium foliar application on some agronomic traits, seed gluten and starch contents of wheat subjected to water deficit stress. Not Bot Horti Agrobot Cluj Napoca 41: 201-207.

41. Bakhtiari M, Moaveni $P$, Sani $B(2015)$ The effect of iron nanoparticles spraying time and concentration on wheat. Biological Forum 7: 679-683.

42. Li X, Zhou Z, Lu D, Dong X, Xu M, et al. (2014) The effect of pristine carbonbased nanomaterial on the growth of green gram sprouts and $\mathrm{pH}$ of water Nanoscale Res Lett 9: 583 .

43. Khodakovskaya M, Dervishi E, Mahmood M, Xu Y, Li Z, et al. (2009) Carbon nanotubes are able to penetrate plant seed coat and dramatically affect seed germination and plant growth. ACS Nano 3: 3221-3227

44. Mondal A, Basu R, Das S, Nandy P (2011) Beneficial role of carbon nanotubes on mustard plant growth: an agricultural prospect. J Nanopart Res 13: 4519-4528.

45. Hao Y, Yu F, Lv R, Ma C, Zhang Z, et al. (2016) Carbon Nanotubes Filled with Different Ferromagnetic Alloys Affect the Growth and Development of Rice Seedlings by Changing the C: N Ratio and Plant Hormones Concentrations. PloS one 11: e0157264.

46. Wang X, Han H, Liu X, Gu X, Chen K, et al. (2012) Multi-walled carbon nanotubes can enhance root elongation of wheat (Triticum aestivum) plants. J Nanopart Res 14: 1-10

47. Barik TK, Sahu B, Swain V (2008) Nanosilica-from medicine to pest control. Parasitol Res 103: 253-258.

48. Gajbhiye M, Kesharwani J, Ingle A, Gade A, Rai M (2009) Fungus-mediated synthesis of silver nanoparticles and their activity against pathogenic fungi in combination with fluconazole. Nanomedicine 5: 382-386.

49. Prasad R, Kumar V, Prasad KS (2014) Nanotechnology in sustainable agriculture: present concerns and future aspects. Afr J Biotechnol 13: 705-713.

50. Hamdi H, De La Torre-Roche R, Hawthorne J, White JC (2015) Impact of non-functionalized and amino-functionalized multiwall carbon nanotubes on pesticide uptake by lettuce (Lactuca sativa L.). Nanotoxicol 9: 172-180.

51. Suriyaprabha R, Karunakaran G, Yuvakkumar R, Rajendran V, Kannan N (2012) Silica nanoparticles for increased silica availability in maize (Zea mays. L) seeds under hydroponic conditions. Curr Nanosci 8: 902-908.

52. Tripathi DK, Singh S, Singh VP, Prasad SM, Dubey NK, et al. (2016) Silicon nanoparticles more effectively alleviated UV-B stress than silicon in wheat (Triticum aestivum) seedlings. Plant Physiol Biochem.

53. Tripathi DK, Singh VP, Prasad SM, Chauhan DK, Dubey NK (2015) Silicon nanoparticles (SiNp) alleviate chromium (VI) phytotoxicity in Pisum sativum (L.) seedlings. Plant Physiol Biochem 96: 189-198.
54. Tripathi DK, Singh S, Singh VP, Prasad SM, Chauhan DK, et al. (2016) Silicon nanoparticles more efficiently alleviate arsenate toxicity than silicon in maize cultivar and hybrid differing in arsenate tolerance. Front Environ Sci 4: 46.

55. Siddiqui $\mathrm{MH}, \mathrm{Al}-$ Whaibi $\mathrm{MH}$ (2014) Role of nano-SiO in germination of tomato (Lycopersicum esculentum seeds Mill.). Saudi J Biol Sci 21: 13-17.

56. Sathiyabama M, Charles RE (2015) Fungal cell wall polymer based nanoparticles in protection of tomato plants from wilt disease caused by Fusarium oxysporum f. sp. Iycopersici. Carbohyd Polym 133: 400-407.

57. Martínez-Ballesta MC, Zapata L, Chalbi N, Carvajal M (2016) Multiwalled carbon nanotubes enter broccoli cells enhancing growth and water uptake of plants exposed to salinity. J Nanobiotechnol 14: 42.

58. Moll J, Gogos A, Bucheli TD, Widmer F, Heijden MG (2016) Effect of nanoparticles on red clover and its symbiotic microorganisms. J Nanobiotechnol 14: 36.

59. Abdel-Aziz HM, Hasaneen MN, Omer AM (2016) Nano chitosan-NPK fertilize enhances the growth and productivity of wheat plants grown in sandy soil. Spanish J Agric Res 14: 0902.

60. Ajirloo AR, Shaaban M, Motlagh ZR (2015) Effect of K Nano-Fertilizer and $\mathrm{N}$ Bio-Fertilizer on Yield and Yield Components of Tomato (Lycopersicon esculentum L.). Int J Adv Biol Biom Res 3: 138-143.

61. Farnia A, Ghorbani A (2014) Effect of K nano-fertilizer and N bio-fertilizer on yield and yield components of red bean (Phaseolus vulgaris L.). Int J Biosci 5: 296-303.

62. Davarpanah S, Tehranifar A, Davarynejad G, Abadía J, Khorasani R (2016) Effects of foliar applications of zinc and boron nano-fertilizers on pomegranate (Punica granatum cv. Ardestani) fruit yield and quality. Sci Hortic 210: 57-64.

63. Liu R, Lal R (2014) Synthetic apatite nanoparticles as a phosphorus fertilizer for soybean (Glycine max). Scientific Reports 4: 5686.

64. Wang P, Lombi E, Zhao FJ, Kopittke PM (2016) Nanotechnology: A New Opportunity in Plant Sciences. Trends Plant Sci 21: 699-712.

65. The Project on Emerging Nanotechnologies (2013) Consumer products inventory An inventory of nanotechnology-based consumer products introduced on the market. The Project on Emerging Nanotechnologies. Washington D.C., USA

66. Haub C, Gribble J, Jacobsen L (2011) World Population Data Sheet 2011 Population Reference Bureau, Washington, USA.

67. Tilman D, Balzer C, Hill J, Befort BL (2011) Global food demand and the sustainable intensification of agriculture. Proc Natl Acad Sci USA 108: 20260-20264.

68. (2007) Tackling global poverty. Nat Nanotechnol 2: 661.

69. UN Millennium Project (2005) Innovation: applying knowledge in development Task Force on Science, Technology, and Innovation.

70. Mukhopadhyay SS (2014) Nanotechnology in agriculture: prospects and constraints. J Nanotechnol Sci Appl 7: 63-71.

71. Mishra V, Mishra RK, Dikshit A, Pandey AC (2014) Interactions of Nanoparticles (NPs) with Plants: An Emerging Prospective in Agriculture Industry. In: Emerging Technologies and Management of Crop Stress Tolerance. Ahmad P (ed). Volume 1. Elsevier Inc., USA. 